\title{
Long-term treatment with low-dose medicine in chronic childhood eczema: a double-blind two-stage randomized control trial
}

R. Carello ${ }^{1 *+}$, L. Ricottini ${ }^{2 \dagger}$, V. Miranda ${ }^{2}$, P. Panei ${ }^{3}$, L. Rocchi ${ }^{1}$, R. Arcieri ${ }^{3}$ and E. Galli ${ }^{1}$

\begin{abstract}
Background: The efficacy of low-dose medicine (LDM) in childhood mild/moderate eczema is not known. We conducted a double-blind, two-stage, randomized, placebo-controlled clinical trial, lasting 23 months, to address this issue.

Method: Eighty children with chronic mild/moderate eczema were randomly allocated to Group A (placebo) or Group B (treatment group; Galium-Heel ${ }^{\oplus}$, a low-dose multicomponent medicine based upon natural substances; Guna-Interleukin 12 and Guna-Interferon- $\gamma$ administered twice a day for six non-consecutive months for each stage). LDM is characterized by the use of biological molecules, such as cytokines, neuropeptides, growth factors, hormones at very low concentrations, which correspond to physiological levels within the human body. The dosage of the cytokines used in this trial (IFN- $\gamma$ and IL-12) is $10 \mathrm{fg} / \mathrm{ml}$. The SCORAD index was evaluated by the same operator: subjects with a SCORAD index below 20 were considered to have mild eczema (61/80; mean: 10.79), whereas a SCORAD index between 20-50 indicated moderate eczema (19/80; mean: 26.84). The data of 66/80 children were analyzed in stage 1 and those of 62/66 children in stage 2. The primary outcome measure was reduction of eczema severity assessed by the SCORAD index. Secondary outcomes were disease-free interval, and treatment safety and tolerability.
\end{abstract}

Results: The decrease in disease severity was greater in Group B than in Group A already in stage 1 (a decrease 63. $9 \%$ versus $53.2 \%$ ), but the difference was not significant ( $p=0.16$ ). Moreover, subjective symptoms (itching and sleep disturbances) initially decreased and then worsened in Group A, whereas itching decreased linearly and sleep disturbances decreased significantly ( $p=0.049$ ) in Group B.

Conclusions: Preliminary evidence suggests potential benefit, but further work is needed to validate this approach. Trial registration: The trial was registered with EudraCT number 2010-018640-13 through the database of the National Clinical Trials Monitoring Centre Database (Osservatorio delle Sperimentazioni Cliniche, OsSC) of the Italian Medicines Agency.

Keywords: Eczema, Immunomodulation, Low-dose medicine, SCORAD index

\footnotetext{
* Correspondence: carellorossella@gmail.com

${ }^{\dagger}$ Equal contributors

'Department of Pediatric Allergy, San Pietro Hospital Fatebenefratelli, Via

Cassia, 600 Rome, Italy

Full list of author information is available at the end of the article
} International License (http://creativecommons.org/licenses/by/4.0/), which permits unrestricted use, distribution, and reproduction in any medium, provided you give appropriate credit to the original author(s) and the source, provide a link to the Creative Commons license, and indicate if changes were made. The Creative Commons Public Domain Dedication waiver (http://creativecommons.org/publicdomain/zero/1.0/) applies to the data made available in this article, unless otherwise stated. 


\section{Background}

Eczema is the most frequent chronic inflammatory condition in childhood; indeed it affects up to $20 \%$ of children and starts in the first years of life [1-4]. Genetic, epigenetic and environmental factors, and disturbed skin barrier function as well as innate and adaptive immune defects, are associated with eczema onset, although the pathogenic mechanisms are not fully understood $[2,3$, 5]. It is a frustrating condition for both patients and caregivers because intense pruritus and sleep disturbances can be intractable, and can negatively impact on school, social and family life thereby resulting in psychological difficulties for all the family, and a high socioeconomic burden [6, 7]. Conventional treatment of moderate-severe eczema may not be sufficient to control the activity of skin lesions, and a small subset of children require more aggressive systemic therapy which is not without side effects [8-10].

Low-dose medicine (LDM) is a new therapeutic approach theorized and developed starting from the most recent knowledge in molecular biology, psycho-neuroendocrine-immunology, and research results in the field of low dose pharmacology. The most intriguing aspect of LDM is the efficacy of oral administration of low dose "signaling molecules". The use of physiological low doses (predominantly nanograms-femtograms) per os in LDM is made possible by the application of SKA (Sequential Kinetic Activation) technology [11, 12]. SKA is a sophisticated drug delivery system, developed according to a pharmaceutical techniques based upon a mechanical process.

The action mechanism of SKA low dose cytokines consists in sensitization and activation of some units of cellular (or plasmatic) receptors in virtue of their low concentration, practically in their physiological working range between $10^{-12} \mathrm{M}$ and $10^{-15} \mathrm{M}$ [13]. LDM exerts pharmacomodulatory activity that can restore the homeostatic balance between the various lymphocyte populations, particularly in allergic and inflammatory diseases. In Gariboldi et al., low-dose concentrations of IL-12 and IFN- $\gamma$ have been used in the in vivo treatment of experimental allergic bronchial asthma (in an animal model) with very encouraging results [14]. Cardani et al. demonstrated that oral administration of low-dose IL-10 and Ab anti-IL1 is able to control intestinal inflammation in an in vivo animal model of IBD (Inflammatory Bowel Disease) [15]. Roberti ML et al. demonstrated the immunomodulatory activity of IL-4, IL-10, and IL-11 in psoriasis vulgaris [16].

The purpose of our double-blind, two-stage randomized clinical trial was to assess the clinical efficacy and safety of long-term LDM treatment in children affected by mild/moderate chronic eczema.

\section{Methods}

\section{Study design}

The aim of this double-blind, two-stage, randomized, placebo-controlled clinical trial was to evaluate the efficacy and safety of long-term treatment ( 23 months) with LDM $v s$ placebo in children with chronic mild/moderate eczema. Patients were randomized into either Group A (placebo group) or Group B (treatment group). In the first stage, all randomized children assumed LDM or placebo for 6 non consecutive months over a period of 8 months, followed by a 6 month follow-up (Fig. 1). In the second stage, non-responders to LDM were rerandomized to receive either LDM or placebo with the same modality as in the first stage, followed by a onemonth follow-up (Fig. 2), whereas responders continued the same treatment (LDM or placebo) as in the first stage of the study.

Children in an acute phase of the disease (see below) were screened by the Clinical Screening Operative Unit, which is constituted by pediatricians operating in the Lazio region, and enrolled at the Department of Pediatric Allergy, San Pietro Hospital Fatebenefratelli (Rome, Italy). Inclusion criteria were children affected by chronic mild/moderate eczema (SCORAD index: $<6-<40$ ), with at least 4 relapses per year, and with onset of skin lesions at least 6 months before the study (all children were in an acute phase of the disease upon enrolment); children with IgE-mediated eczema (i.e., children who tested positive to specific in vivo and/or in vitro tests, and children with non-IgE-mediated eczema (negative to specific in vivo and/or in vitro tests); and written informed consent of parents and guardians to the study. Exclusion criteria were: systemic treatment with corticosteroids and antihistamines, with topical calcineurin inhibitors (tacrolimus and/or pimecrolimus) or with specific immunotherapy in the three months before the study; and severe eczemaassociated systemic disorders.

\section{Patients}

Children were enrolled at the Department of Pediatric Allergy, San Pietro Hospital Fatebenefratelli, Rome between February 2010 and July 2013. A total of 105 children were screened and 80 were enrolled and randomized as shown in the clinical trial flow diagram (Fig. 3 and Table 1). In detail, 43 boys and 37 girls (mean age: 73.77 months; range: 18 months -16 years) with mild/moderate chronic eczema, diagnosed according to the revised Hanifin and Rajka criteria [17], were enrolled in the study. Eczema was considered chronic if it lasted at least 6 months (relapses $\geq 4 /$ year). Subjects in remission during screening were excluded.

Disease severity was assessed with the Scoring Atopic Dermatitis (SCORAD) index that rates the extent and 

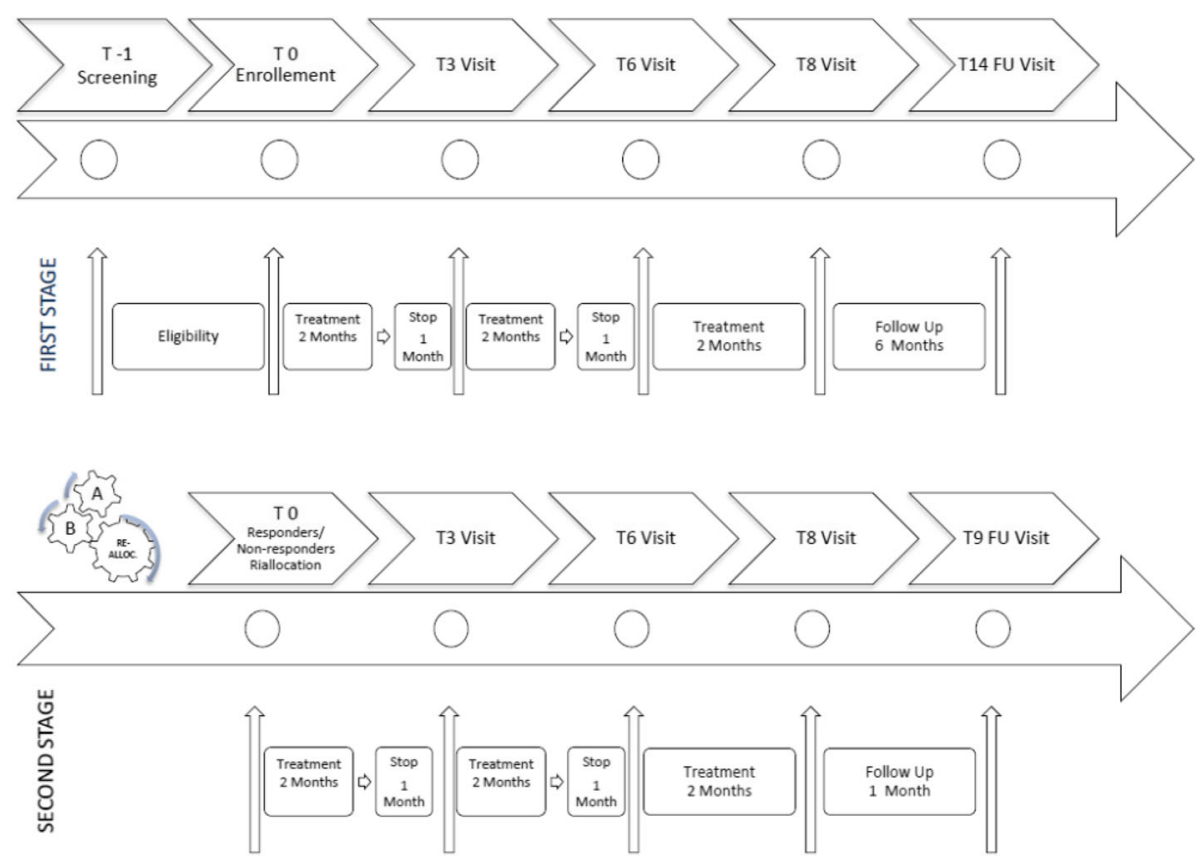

Fig. 1 Visits and treatment during the first and second stages of the study

intensity of eczema, and subjective symptoms, namely pruritus and sleeplessness [18]. The SCORAD index was evaluated by the same operator (R.C.) throughout the study. Subjects with a SCORAD index below 20 were considered to have mild eczema (61/80; mean: 10.79), whereas a SCORAD index between 20 and 50 indicated moderate eczema (19/80; mean: 26.84). None of the enrolled children suffered from other chronic diseases or was taking oral steroids, antihistamines or topical calcineurin inhibitors, specific immunotherapy or immunosuppressive therapy at the time of investigation.

The data of each child, including adverse events, were recorded on an electronic case report form at each visit. At time zero (T0), each patient was given a clinical diary on which to record to symptomatology and the use, if any, of symptomatic treatment during the acute phase.

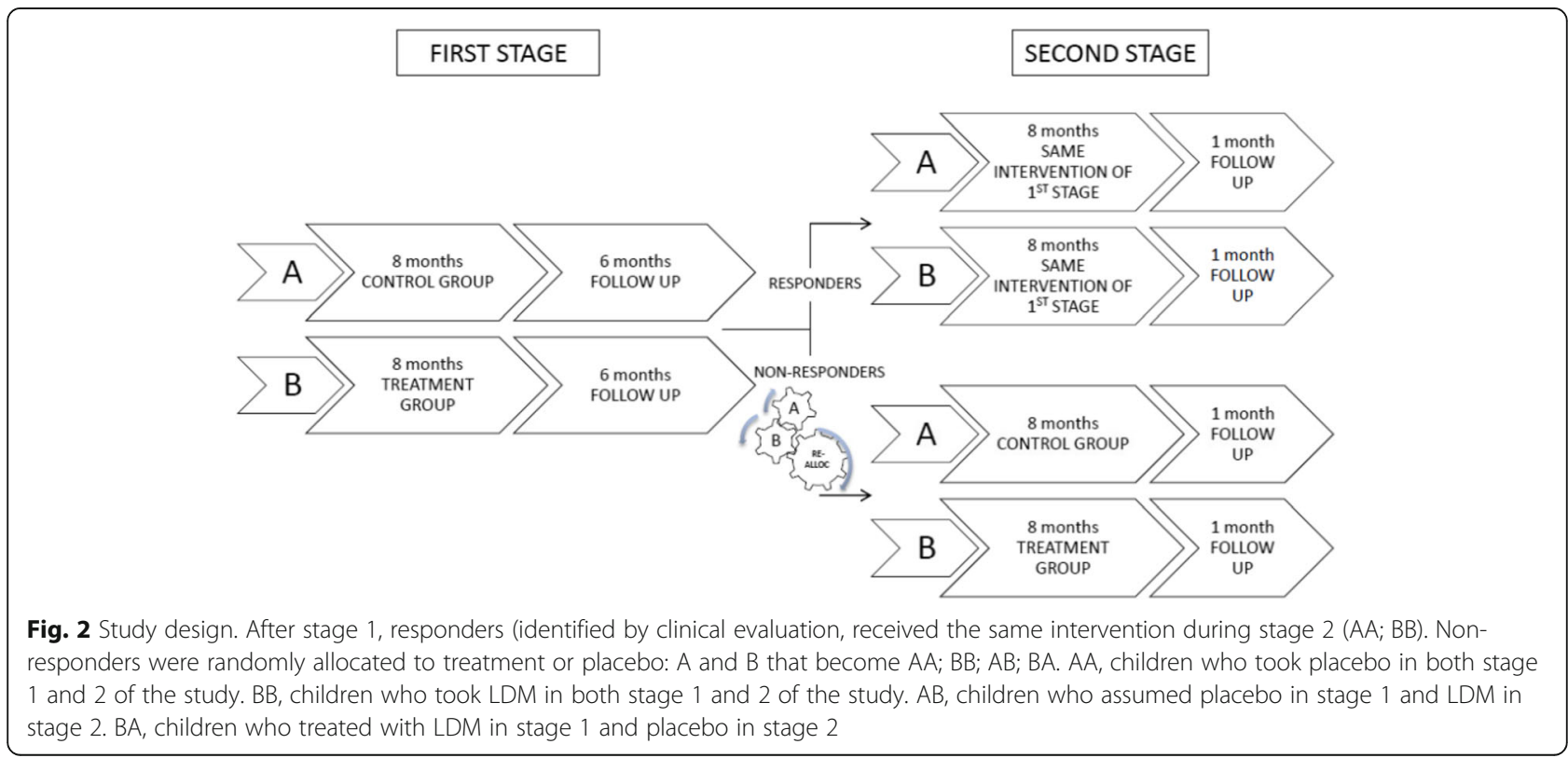




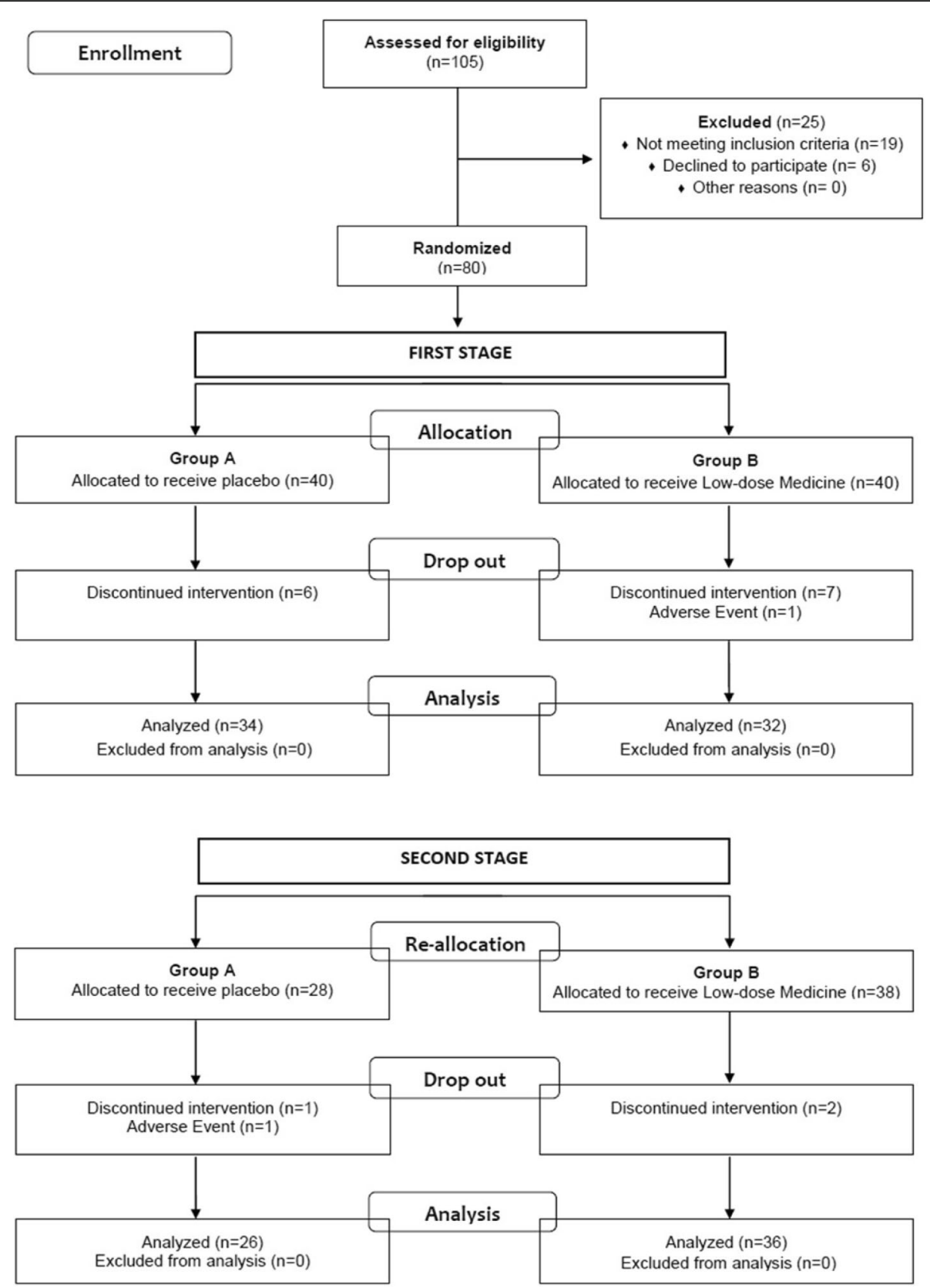

Fig. 3 Clinical trial flow diagram (Consort 2010) of the first and second stage of the study

Table 1 Distribution of epidemiological and clinical characteristics at randomization

\begin{tabular}{llll}
\hline Variable & Group A & Group B & $p$ value \\
\hline SCORAD index (mean value) \pm SD & $13.93 \pm 8.28$ & $14.71 \pm 7.64$ & 0.66 \\
\% Boys & 55.0 & 52.5 & 7.99 \\
Mean age (months) \pm SD & $69.0 \pm 43.6$ & $78.6 \pm 50.9$ & 0.37 \\
Median age (months) & 64.5 & 60.5 & 0.48 \\
Age at diagnosis (months) & 51.2 & 68.2 & 0.83 \\
lgE kU/l (mean value) \pm SD & $373.5 \pm 929.4$ & $409.6 \pm 561.4$ & 0.58 \\
\% positive prick test & 42.5 & 47.5 & \\
\hline
\end{tabular}




\section{Treatment}

SKA-cytokines were prepared by GUNA Laboratories (GUNA S.p.a., Milan, Italy) using the standardized method [14]. IFN- $\gamma$ and IL-12 were activated by sequential serial dilution (1:100) in 30\% hydro-alcoholic solution and kinetically energized by a shaking procedure (vertical shaking; $10 \mathrm{~cm}$ motion range; shaking speed corresponding to 100 oscillations in $10 \mathrm{~s}$ ). Subjects who satisfied the eligibility criteria were randomly allocated to Group A or Group B, and identified by their initials and a serial number. Group B (treatment group) was treated with Galium-Heel ${ }^{\circledR}$ (Biologische Heilmittel Heel GmbH, Baden Baden, Germany), Guna-Interleukin 12 and Guna-Interferon $\gamma$ at the concentration of $10 \mathrm{fg} / \mathrm{ml}$ SKA $[11,14,19]$ in hydro-alcoholic solution $30 \%$. Each preparation was orally administered (8 drops in children aged $\leq 5$ years and 15 drops in children above the age of 5) twice daily for 6 non-consecutive months in each stage. This concentration is far from being toxic, therefore the concept of pharmacological use in terms of "pro-kg amount" would be nonsense. Group A received placebo (hydro-alcoholic solution 30\% without active ingredients) with the same mode of administration.

During the study, all children received conventional therapy (topical steroids, topical or oral antibiotics and antihistamines) when necessary to alleviate symptoms.

\section{Outcomes}

The primary outcome measure was a decrease in severity based on the SCORAD index. Secondary outcomes were disease-free interval, treatment safety and tolerability, skin prick test for inhalant and food allergens, skin prick-by-prick, total and specific IgE assessment and serum cytokine level of IL-4, IL-10, IL-12, IL-13, IFN- $\gamma$.

\section{Sample size}

The required sample size was estimated with respect to the variation in the SCORAD index, based on the paired Student's t test two-tailed comparison of the mean value between Groups A and B at baseline, and 3, 6, 8 and 14 months thereafter. We recorded differences in the SCORAD index in terms of increase and decrease, and therefore we considered both improvements (a decrease in the SCORAD index) and worsening (an increase in the SCORAD index). A difference of $30 \%$ between baseline to 14 months was considered clinically relevant. Finally, assuming a power $1-\beta=0.80$ and a probability of a type I error $\alpha=0.05$, the required sample size was 128 .

\section{Randomization}

Children who satisfied the eligibility criteria were randomized using software with a 128 random list for the two groups (A and $\mathrm{B})$ in a 1:1 ratio. Block randomization was performed with a block size of 16 . The subjects were assigned to Group A or Group B, according to the sequential order of enrolment. A second 128 random list was generated for the second stage of the study (Fig. 2 ). The random allocation sequence was generated by biostatisticians (Department of Pharmacology and Therapeutic Research, Italian National Institute of Health, Rome, Italy).

\section{Sample collection and methods}

The timing of sampling is shown in Fig. 1. IL-4, IL-10, IL-12, IL-13 and IFN- $\gamma$ were quantified by a doubleantibody sandwich ELISA method according to the manufacturer's instructions (Thermo Scientifics, Waltham, MA, USA). Skin prick tests were performed and interpreted as previously described [20] with commercial inhalant and food allergens (Stallergenes, Milan, Italy). Prick-by prick-tests were performed directly with the offending food. Total serum IgE and allergen-specific IgE were quantified in the sera of subjects with a fluorescence enzyme immunoassay ImmunoCAP (Phadia/Thermo Fisher Scientific Inc., Uppsala, Sweden) in accordance with the product manual with a lower detection limit of $0.35 \mathrm{kU} / \mathrm{l}$ and a maximum limit of $100 \mathrm{kU} / \mathrm{l}$.

\section{Statistical analysis}

The data were analyzed with SPSS 22 and OpenEpi 3.02 software packages. Categorical variables are presented as absolute and percent frequencies, and quantitative variables are showed as means \pm standard deviations. The data were analyzed separately from $\mathrm{T} 0$ to $\mathrm{T} 3$, from $\mathrm{T} 3$ to T6, from T6 to T8, and from T8 to T14 to assess the efficacy of the treatment in reducing the SCORAD index ("absolute effectiveness"). We also compared the two groups at different times to evaluate the relative effectiveness of the two treatments. We calculated the probability (odds ratio; OR) of the disease-free interval between the study groups, using person/time to normalize the difference in the number of subjects in each group, and the difference in time of the presence of each subject in the study. We calculated the OR of being a non-responder to therapy by comparing Group A and Group B. For any reference period, only subjects with data at baseline and at least one observation during the study were included in the analysis. We performed an intention-to-treat analysis and per-protocol analysis. An interim analysis was carried out at the end of the first phase of the study (data not shown).

\section{Results}

As shown in the flowchart (Fig. 3), 66 of the 80 enrolled children were included in the statistical analysis of the first stage of the study: 40 in Group A and 40 in Group B. There were 14 drop-outs $(17.5 \%)$ in this stage. 
Thirteen discontinued medication (6 in Group A and 7 in Group B), and one child in Group B experienced an adverse event (Fig. 3). In the second stage of the study, 4 (7.1\%) children discontinued the intervention (2 in Group A and 2 in Group B). One child in Group A went abroad and the other experienced an adverse event. The two children in Group B discontinued for non compliance as indicated by their parents. There were no significant intergroup differences in terms of gender, age and clinical findings (Table 1).

\section{SCORAD analysis}

In the first stage of the study, the SCORAD index decreased between T0 and T14 in both groups. In Group A (placebo) it decreased by $41.5 \%$ between $\mathrm{T} 0$ and $\mathrm{T} 8$ $(p=0.001)$, and by $53.2 \%$ between T0 and T14 $(p<$ 0.001). In Group B (treatment), it decreased by $53.8 \%$ between T0 and T8 $(p<0.001)$, and by $63.9 \%$ between T0 and T14 $(p<0.001)$. The overall decrease in the

Table 2 SCORAD index at the various times of stage 1 in groups $A$ and $B$, and in stage 2 for groups A (placebo), B (treatment), placebo/placebo (AA) and treatment/treatment (BB) groups

\begin{tabular}{|c|c|c|c|c|c|c|}
\hline & $\mathrm{N}$ & Mean & $\mathrm{SD} \pm$ & $\%$ of change vs T0 & \multicolumn{2}{|c|}{$p$ value } \\
\hline \multicolumn{7}{|l|}{ FIRST STAGE } \\
\hline \multicolumn{7}{|c|}{ Group A placebo } \\
\hline T0 & 40 & 13.93 & 8.28 & & & \\
\hline T3 & 37 & 11.00 & 11.08 & 21.0 & 0.2 & \\
\hline T6 & 34 & 10.15 & 11.71 & 27.1 & 0.12 & \\
\hline T8 & 33 & 8.15 & 4.15 & 41.5 & 0.001 & \\
\hline T14FU & 32 & 6.53 & 3.21 & 53.2 & 0.0001 & \\
\hline total & 177 & 10.18 & 8.83 & & & \\
\hline \multicolumn{7}{|c|}{ Group B treatment } \\
\hline T0 & 40 & 14.71 & 7.65 & & & \\
\hline T3 & 35 & 9.74 & 10.25 & 33.8 & 0.0218 & \\
\hline T6 & 35 & 8.00 & 10.45 & 45.6 & 0.0026 & \\
\hline T8 & 33 & 6.79 & 4.08 & 53.8 & 0.001 & \\
\hline T14FU & 33 & 5.30 & 3.82 & 63.9 & 0.0001 & \\
\hline total & 177 & 9.17 & 8.47 & & & \\
\hline \multicolumn{7}{|c|}{ SECOND STAGE } \\
\hline \multicolumn{7}{|c|}{ Group AA placebo/ placebo } \\
\hline T0 & & 22 & 6.23 & 3.13 & & \\
\hline T8 & & 22 & 5.86 & 6.32 & 5.9 & 0.81 \\
\hline T9FU & & 22 & 4.64 & 8.30 & 25.5 & 0.41 \\
\hline \multicolumn{7}{|c|}{ Group BB treatment/treatment } \\
\hline T0 & & 27 & 5.22 & 3.75 & & \\
\hline T8 & & 27 & 5.07 & 3.05 & 2.9 & 0.87 \\
\hline T9FU & & 27 & 3.52 & 2.59 & 32.6 & 0.058 \\
\hline
\end{tabular}

SCORAD index was greater in Group B even if not significantly. As shown in Table 2, there were no intergroup differences at the various time points evaluated, although apparently there was a trend towards a possibly better clinical improvement in Group B children.

As we had expected, the comparison between the SCORAD groups was not significant (Student's $\mathrm{t}$ test: $p=0.29$ at $\mathrm{T} 8$, and $p=0.16$ at T14), and therefore this endpoint wasn't reached.

At the end of the first stage, responders $(n=37$; $\mathrm{AA} / \mathrm{BB}$, i.e., placebo in both stages/treatment in both stages) continued the same treatment as in stage 1 (Table 2). Children classified as non-responders $(n=$ 28) were randomly reallocated to placebo or to treatment $(\mathrm{AB} / \mathrm{BA} / \mathrm{AA} / \mathrm{BB})$.

In stage 2, there were no significant decreases in the mean SCORAD index within Group AA at T0, T8 or T9. In Group BB there was a decrease in the SCORAD index of $33 \%$ between T0 and T9 $(p=0.058)$ and of $31 \%$ between T8 and T9 $(p=0.049)$ (Table 2$)$. In the stage 2 reallocation, we did not analyze the SCORAD index in groups $\mathrm{AB}$ and $\mathrm{BA}$ because of the low numbers of children in these groups.

Table 3 Analysis of the clinical diaries for itching and sleep disturbances

\begin{tabular}{|c|c|c|c|}
\hline & TO & T8 & T14 FU \\
\hline \multicolumn{4}{|l|}{ Group A placebo } \\
\hline \multicolumn{4}{|l|}{ Pruritus } \\
\hline $\mathrm{N}$ & 23 & 23 & 18 \\
\hline Mean & 24.91 & 19.74 & 32.61 \\
\hline $\mathrm{SD} \pm$ & 22.52 & 24.11 & 39.99 \\
\hline \multicolumn{4}{|l|}{ Sleep disturbance } \\
\hline $\mathrm{N}$ & 23 & 23 & 18 \\
\hline Mean & 9.13 & 5.87 & 13.33 \\
\hline $\mathrm{SD} \pm$ & 18.36 & 16.74 & 30.24 \\
\hline \multicolumn{4}{|l|}{ Group B treatment } \\
\hline \multicolumn{4}{|l|}{ Pruritus } \\
\hline $\mathrm{N}$ & 21 & 21 & 13 \\
\hline Mean & 24.33 & 15.76 & 15.67 \\
\hline $\mathrm{SD} \pm$ & 22.45 & 17.61 & 20.33 \\
\hline \multicolumn{4}{|l|}{ Sleep disturbance } \\
\hline $\mathrm{N}$ & 21 & 21 & 13 \\
\hline Mean & 5.62 & 2.95 & 0.00 \\
\hline $\mathrm{SD} \pm$ & 14.56 & 11.27 & 0.00 \\
\hline$p$ value B vs A Pruritus & 0.93 & 0.53 & 0.13 \\
\hline $\begin{array}{l}p \text { value } \mathrm{B} \text { vs A } \\
\text { Sleep disturbance }\end{array}$ & 0.48 & 0.50 & 0.08 \\
\hline
\end{tabular}




\section{Disease-free interval}

A total of 1482 clinical diaries (924 concerning stage 1 and 558 stage 2) were collected. These contained information about subjective symptoms (pruritus and sleep disturbances) and about the use of drugs during the 23 months of the study. As shown in Table 3, pruritus and sleep disturbances decreased, albeit not significantly $(p=0.07)$, in Group A between T0 and T8, while both symptoms were higher, but not significant, between T9 and T14 versus baseline. In Group B, the pruritus score decreased between $\mathrm{T} 0$ and $\mathrm{T} 8$, and remained stable between T9 and T14. In the same group, sleep disturbances decreased $50 \%$ between T0 and T8 $(p<0.001)$, and were absent at T14. However the only statistically significant difference between groups A and B was observed in sleep disturbances at time T14 $(p=0.081)$ (Table 3).

We analyzed the use of symptomatic drugs as per time/person expressed in months, which is the sum of the time during which each single child took symptomatic drugs (Table 4). During stage 1, Group A children assumed drugs for 30 months/person between T0 and T8 and between T9 and T14, whereas Group B assumed symptomatic drugs for 16 months/person between T0 and $\mathrm{T} 8$ and 8 months/person between $\mathrm{T} 9$ and T14. Therefore, Group B assumed drugs between T0 and T8 for less time than did Group A. Moreover, Group $B$ assumed drugs for significantly less time during the T9-T14 period compared with Group A (Fisher's exact test $=0.001$ ).

\section{Safety and tolerability}

Two adverse events were recorded: one in Group A and one in Group B. The one in Group B occurred during stage 1 of the study, between T8 and T14, and consisted in continuous pain in the right leg and difficulty in walking, which did not regress after discontinuation of the treatment. This child was considered a drop out. The analysis of this event using the method reported by Naranjo et al. [21] did not reveal a correlation between the drug and the event. The event recorded in Group A occurred during stage 2 at T3, and consisted of hidradenitis festering. This subject was considered a drop out. The total percent of drop-outs was $25 \%$, and about $70 \%$ of subjects left the study during stage 1 . The main cause of drop out was difficulty in adhering to the protocol over such a long period.

\section{Cytokines}

In the attempt to shed light on changes that may occur in the immune system during treatment with LDM or placebo, we measured the inflammatory cytokines IL-4, IL-10, IL-12, IL-13 and IFN- $\gamma$ in children who were willing to undergo sampling during each observation, 45 in stage 1 (22 in Group A and 23 in Group B) and 8 in stage 2 (4 in Group A and 4 in Group B). We did not find changes in the levels of inflammatory cytokines, although there was a wide spectrum of values at the diverse times of observation in both groups. Furthermore, there were no intra- or intergroup differences in cytokine concentration between Group A and Group B, except for a reduction in IL-13 in function of time in both groups (data not shown). Similarly, total IgE levels, the prick test for inhalants, and prick-by-prick for food did not differ between the groups at any time in the two stages.

\section{Discussion}

Little is known about the efficacy of low-dose compounds in eczema [22-27]. In the first stage of this study, disease severity decreased in both groups, although more so in treated than in untreated children $(63.9 \%$ vs $53.2 \%)$ (Table 2). The improvement in the untreated children may be partially explained by the clinical practice of treating the skin of patients using detergents and particular emollients and moisturizers. As shown in Table 2, the improvement of the SCORAD index was even more evident in the group that took the drug in both stages (T0 vs T9, second stage $p=0.058$; T8 vs T9, second stage $p=0.049$ ). These results are in line with the hypothesis that LDM acts by progressively modulating the immune system [16-19] until it reaches homeostasis, which is maintained during follow-up (T9T14/T8-T9). In fact, Group B maintained a low SCORAD index using much less conventional therapy than Group A during follow-up (Table 4).

From an ethical viewpoint, the placebo group should not have been left without symptomatic drugs; therefore

Table 4 Differences between groups A and B at stage 1 at T0-T8 and T9-T14

\begin{tabular}{|c|c|c|c|c|c|c|c|c|}
\hline Variable & $\begin{array}{l}\text { Group A } \\
\text { T0-T8 }\end{array}$ & $\begin{array}{l}\text { Group B } \\
\text { T0-T8 }\end{array}$ & $\begin{array}{l}\text { Difference between } \\
\text { B-A groups }\end{array}$ & $P$ value & $\begin{array}{l}\text { Group A } \\
\text { T9-T14 FU }\end{array}$ & $\begin{array}{l}\text { Group B } \\
\text { T9-T14 FU }\end{array}$ & $\begin{array}{l}\text { Difference between } \\
\text { B-A groups }\end{array}$ & $p$ value \\
\hline$\%$ decrease of the SCORAD index & 41.5 & 53.8 & 12.3 & 0.014 & 19.9 & 21.9 & 2.0 & 0.77 \\
\hline Conventional therapy (months/person) & 30 & 16 & -14 & 0.074 & 30 & 9 & -21 & 0.077 \\
\hline$\%$ of patients treated with steroids ${ }^{a}$ & 32.1 & 23.1 & -9.0 & 0.073 & 17.9 & 15.3 & -2.6 & 0.15 \\
\hline$\%$ of patients treated with antihistamines ${ }^{a}$ & 35.7 & 19.2 & -16.5 & 0.003 & 32.1 & 11.5 & -20.6 & 0.028 \\
\hline
\end{tabular}

${ }^{a}$ We considered treated with steroids or antihistamines subjects that took at least one medication during the study. (FU: follow-up) 
both groups have had access to symptomatic therapy. In both groups the SCORAD reduction was similar, but the consumption of symptomatic drugs was significantly lower in Group B.

The results of the disease-free interval support the hypothesis that LDM acts by progressively modulating the immune system. In fact, the follow-up data showed an improvement in the SCORAD index in the two groups at both stages of the study, but the effect was more pronounced in Group B. Moreover, the finding that itching and sleep disturbances improved in Group A children between $\mathrm{T} 0$ and $\mathrm{T} 8$, and worsened greatly between $\mathrm{T} 8$ and T14 follow-up confirms that eczema is a complex disease in which the psychological aspect plays an important role [7]. Itching and sleep disturbances improved in Group B children between T0 and T8, and between T8 and T14 follow-up thereby confirming the long-term immunomodulation of LDM (Table 3). Subjective symptoms improved in Group B between T0 and T8 and this improvement was maintained during T8-T14 (Table 3). This finding is even more relevant considering that the consumption of symptomatic drugs was 30\% lower in Group B than in Group A (9 months/person $v s$ 30 months/person; $p=0.001$ ) (Table 4 ) with an improvement in the family management of eczema according to the parents and children during control visits. Sleep disturbances improved greatly (T0/T8 first stage $p<0.001)$ in Group B, and were absent in the second stage (Table 3). This is in line with the well known effect of IFN- $\gamma$ in promoting REM or NREM sleep [28-30].

Interferons and cytokines at the concentration of $10 \mathrm{fg} / \mathrm{ml}$, which is a physiological concentration, represent "signaling molecules" able to exert immunomodulatory activity on target cells [16-19]. In a condition of imbalance of the immune system, these biological molecules might be able to restore the balance in overexpressed lymphocyte clones $[14,16]$.

A critical point of "signaling molecules" (and peptides in general) oral administration is represented by their low bioavailability, which is typically less than $1-2 \%$ : for this reason an effective drug delivery system (SKA) is required in order to improve this key parameter. Specific studies about the stability of cytokines at intestinal $\mathrm{pH}$ have never been conducted, nevertheless the abundance of data produced about the pharmacological activity of those oral administered molecules in sub-nanomolar concentrations enhances the hypothesis of a mechanism overcoming the gastro-intestinal barrier. Moreover, it is difficult to investigate the pharmacokinetics of low-dose orally administered cytokines. The limits of sensitivity of current assay techniques do not allow to perform pharmacokinetic tests following the oral administration of the above mentioned proteins at the usual concentrations $(\mathrm{fg} / \mathrm{ml})$. However Tessaro et al. reported that an oral administration of a low dose of rhFSH is able to ameliorate some peculiar features of PCOS (Polycystic Ovary Syndrome) in hyper-androgenized mice [31]. Martin-Martin LS et al. has shown in an open randomized active controlled clinical trial the activity of lowdose SKA IL-4, IL-10, and Ab anti IL-1 versus DMARDs in maintaining low disease activity in patients affected by rheumatoid arthritis in remission after therapy with biological drugs [32].

SKA low dose molecules work by bringing to the system information able to activate auto-regulation mechanisms. This immunomodulating effect could underlie the decrease in the SCORAD index and the clinical improvements seen in our study. In particular, IFN- $\gamma$ is a powerful modulator of the Th2 lymphocyte clone, and IL-12 is a strong signal of induction of IFN- $\gamma$. In addition, IL-4 and IFN- $\gamma$ mirror the Th1/Th2 imbalance and the state of inflammation of eczema. Consequently, the expansion of the Th2 lymphocyte clone can be regulated by administration of low-dose SKA IFN- $\gamma$ and IL12 [14-19]. Consequently, we studied the immunomodulatory effect of IFN- $\gamma$ and IL-12 low-dose SKA. We did not identify a linear variation between blood levels of inflammatory cytokines and the clinical effects observed after administration of low-dose SKA IFN- $\gamma$ and IL-12 (data not shown). Similarly, we were unable to identify changes in the blood concentrations of these molecules that could support the clinical results, probably because of their brief half life and the very low concentration at which they were administered.

In terms of pharmacoeconomics, the advantages of LDM treatments for chronic eczema are compelling, even though it is difficult to compare the costs of a topical/oral symptomatic therapy to an immunomodulating one.

Since LDM therapies are mainly aimed at recovering the homeostasis of the entire system, the need of symptomatic therapies for the management of different and numerous symptoms results to be much lower, as emerged by this clinical trial (Table 3). We can furthermore affirm that the Group B uses the symptomatical treatment in a significantly reduced measure compared to the Group A, even in the follow-up period (Disease Free Interval) (Table 4), this data suggests that low dose treatment can be given according to a reduced therapeutic cycle model.

A limitation of our study is the relatively large number of drop-outs. This was probably due to the long-term nature of the study (nearly 2 years), which, although potentially enabling us to obtain robust clinical data, may have been a deterrent to compliance.

\section{Conclusion}

Preliminary evidence suggests potential benefit, but further work is needed to validate this approach. However, 
in this study, itching, sleep disturbances, and eczema exacerbations were reduced in children treated with LDM compared with conventional therapy, and LDM was well tolerated. Low-dose medicine had good long-term clinical efficacy (reduction of skin lesions, itching and sleeplessness); its benefit persisted during follow-up; it resulted in a reduced intake of symptomatic therapy, was well tolerated and had a good safety profile.

Although there is a need for studies with a more streamlined design to increase compliance and reduce the number of drop-outs, and to obtain more information about the clinical and immunological activity of LDM, the latter can be considered a valid support to conventional treatment in some cases of chronic eczema of mild to moderate intensity.

\section{Abbreviations}

ELISA: Enzyme-linked immunosorbent assay; IFN- $\gamma$ : Interferon- $\gamma_{\text {; }}$ IgE: Immunoglobulin E; IL-12: Interleukin-12; LDM: Low-dose medicine; NREM: Non- rapid eye movement; REM: Rapid eye movement; SCORAD: Scoring atopic dermatitis; SKA: Sequential kinetic activation

\author{
Acknowledgements \\ We wish to thank M. Campanella (Clinical Research Unit Guna S.p.a. \\ Milan, Italy) for her precious technical support in data management. \\ We thank also Jean Ann Gilder (Scientific Communication s.r.l., Naples, Italy) \\ for writing assistance.
}

\section{Ethics approval and consent to partecipate}

Written informed consent was obtained from the parents or the guardian of all children and adolescents participating in the study. The study and the consent procedure was approved by the Ethics Committee of the San Pietro Fatebenefratelli Hospital, Rome. The investigation was carried out in accordance with the principles of the Declaration of Helsinki (Seoul 2008) and Good Clinical Practice guidelines (CPMP/ICH/135/95).

\section{Funding}

This study was funded by Guna S.p.a., Milan, Italy.

\section{Availability of data and materials}

The study database is not available for free access.

\section{Clinical Screening Operative Unit}

Ricottini L., Mischi R., Moretti MT., Roberti ML., Gallese A., De Sanctis F., Manetta F., Tropiano D., Zanda C., Cives C., Pittana L., Ciasco M., Salvatori L., Zirletta E., Del Zoppo P., Gregory S., Falletta S.,Messina M., Palusci A., Totino T, Mazzocchi P. Tudisco L, Valente M. Heuduck P.

\section{Authors' contributions}

EG, LR and VM contributed to the conception and design of the clinical study and to the interpretation of the data. RC, LR and EG contributed to the clinical study and acquisition of data. PP and RA contributed to the design of the clinical study, statistical analysis, and to the interpretation of data. LR was involved in laboratory assistance. All authors contributed to the drafting and revision of the manuscript, and provided final approval of the manuscript for submission.

\section{Consent for publication}

Not applicable

\section{Competing interests}

VM works for the pharmaceutical company Guna S.p.a., Milan, Italy. LR is an external coordinator of the Clinical Research Unit, Guna S.p.a., Milan, Italy.

All the other authors declare no competing interests.

\section{Publisher's Note}

Springer Nature remains neutral with regard to jurisdictional claims in published maps and institutional affiliations.

\section{Author details}

'Department of Pediatric Allergy, San Pietro Hospital Fatebenefratelli, Via Cassia, 600 Rome, Italy. ${ }^{2}$ Clinical Research Unit, Guna S.p.a., Milan, Italy. ${ }^{3}$ Department of Pharmacology and Therapeutic Research, Italian National Institute of Health, Rome, Italy.

Received: 1 June 2017 Accepted: 17 August 2017

Published online: 06 September 2017

\section{References}

1. Flohr C, Mann J. New insights into the epidemiology of childhood atopic dermatitis. Allergy. 2014;69:3-16.

2. Meglio P, Galli E, Maiello N. Atopic dermatitis. In ERS Handbook of Paediatric Respiratory Medicine. 2013:363-9.

3. Schneider L, Tilles $S$, Lio P, Boguniewicz M, Beck L, et al. Atopic dermatitis: a practice parameter update 2012. J Allergy Clin Immunol. 2013;131(2):295-9.

4. Eichenfield LF, Tom WL, Chamlin SL, Feldman SR, Hanifin JM, et al. Guidelines of care for the management of atopic dermatitis: section1. Diagnosis and assessment of atopic dermatitis. J Am Acad Dermatol. 2014:70(2):338-51.

5. Darlenski R, Kazandjieva J, Hristakieva E, Fluhr JW. Atopic dermatitis as a systemic disease. Clin Dermatol. 2014:32(3):409-13.

6. Ersser SJ, Cowdell F, Latter S, Gardiner E, Flohr C et al. Psychological and educational interventions for atopic eczema in children. Cochrane Database 2014 Syst Rev 7; 1:CD004054

7. Lewis-Jones S. Quality of life and childhood atopic dermatitis: the misery of living with childhood eczema. Int J Clin Pract. 2006;60(8):984-92.

8. Galli E, Neri I, Ricci G, Baldo E, Barone M, et al. Consensus conference on clinical management of pediatric atopic dermatitis. Ital J Pediatr. 2016 Mar 2;42:26.

9. Eichenfield LF, Tom WL, Berger TG, Krol A, Paller AS, et al. Guidelines of care for the management of atopic dermatitis: section 2. Management and treatment of atopic dermatitis with topical therapies. J Am Acad Dermatol. 2014;71(1):116-32.

10. Sidbury R, Davis DM, Cohen DE, Cordoro KM, Berger TG, et al. Guidelines of care for the management of atopic dermatitis: section 3. Management and treatment with phototherapy and systemic agents. J Am Acad Dermatol. 2014;71(2):327-49.

11. Radice E, Miranda V, Bellone G. Low-doses of sequential-kinetic-activated interferon- $\gamma$ enhance the ex vivo cytotoxicity of peripheral blood natural killer cells from subjects with early-stage colorectal cancer. A preliminary study. Int Immunopharmacol. 2014;19:66-73.

12. Radice E, Bellone G, Miranda V. Enhancement of the immunostimulatory functions of ex vivo generated dendritic cells from early stage colon cancer subjects by consecutive exposure to low doses of sequential-kineticactivated IL-4 and IL-12. A preliminary study. TransI Oncol. 2015;8(4):327-38.

13. Biancotto A, Wank A, Perl S, Cook W, Olnes MJ, et al. Baseline levels and temporal stability of 27 multiplexed serum cytokine concentrations in healthy subjects. PLoS One. 2013;8(12):e76091.

14. Gariboldi S, Palazzo M, Zanobbio L, Dusio GF, Mauro V, et al. Low dose oral administration of cytokines for treatment of allergic asthma. Pulm Pharmacol Ther. 2009;22:497-510

15. Cardani D, Dusio GF, Luchini P, Sciarabba M, Solimene U, et al. Oral administration of interleukin-10 and anti-IL-1 antibody ameliorates experimental intestinal inflammation. Gastroenterology Research. 2013:6(4):124-33.

16. Roberti ML, Ricottini L, Capponi A, Sclauzero E, Vicenti P. Immunomodulating treatment with low dose interleukin-4, interleukin-10 and interleukin-11 in psoriasis vulgaris. J Biol Regul Homeost Agents 2014:28(1):133-139.

17. Eichenfield LF, Hanifin JM, Luger TA, Stevens SR, Pride HB. Consensus conference on pediatric atopic dermatitis. J Am Acad Dermatol. 2003;49(6):1088-95.

18. Severity scoring of atopic dermatitis: the SCORAD index. Consensus report of the European task force on atopic dermatitis. Dermatology 1993;186:23-31. 
19. Barygina V, Becatti M, Lotti T, Moretti S, Taddei N. Treatment with low-dose cytokines reduces oxidative-mediated injury in perilesional keratinocytes from vitiligo skin. J Dermatol Sci. 2015;79(2):163-70.

20. Galli E, Rocchi L, Carello R, Giampietro PG, Panei P, et al. Serum vitamin D levels and vitamin $D$ supplementation do not correlate with the severity of chronic eczema in children. Eur Ann Allergy Clin Immunol. 2015;47(2):9-15.

21. Naranjo CA, Busto U, Sellers EM, Sandor P, Ruiz I, et al. A method for estimating the probability of adverse drug reactions. Clin Pharmacol Ther. 1981;30:239-45.

22. Linde K, Clausius N, Ramirez G, Melchart D, Eitel F, et al. Are the clinical effects of homeopathy placebo effects? A meta-analysis of placebo controlled trials. Lancet. 1997;350:834-43.

23. Schafer T, Riehle A, Wichmann HE, Ring J. Alternative medicine in allergies prevalence, patterns of use, and costs. Allergy. 2002;57:694-700.

24. Keil T, Witt CM, Roll S, Vance W, Weber K, et al. Homoeopathic versus conventional treatment of children with eczema: a comparative cohort study. Complement Ther Med. 2008;16:15-21.

25. Anderson P. Dinulos JG (2009) atopic dermatitis and alternative management strategies. Curr Opin Pediatr. 2009;21:131-8.

26. Witt CM, Brinkhaus B, Pach D, Reinhold T, Wruck K, et al. Homoeopathic versus conventional therapy for atopic eczema in children: medical and economic results. Dermatology. 2009:219:329-40.

27. Roll S, Reinhold T, Pach D, Brinkhaus B, Icke K, et al. Comparative effectiveness of homoeopathic vs. conventional therapy in usual care of atopic eczema in children: long-term medical and economic outcomes. PLoS One. 2013:8:1-9.

28. Kubota T, JA M, R A B, JM K. Tumor necrosis factor receptor fragment attenuates interferon-induced non-REM sleep in rabbits. J. Neuroimmunol. 2001;119:192-8

29. Sakami S, Ishikawa T, Kawakami N, Haratani T, Fukui A. Coemergence of insomnia and a shift in the Th1/Th2 balance toward Th2 dominance. Neuroimmunomodulation. 2003;10:337-43.

30. Redwine L, Dang J, Hall M, Irwin M. Disordered sleep, nocturnal cytokines and immunity in alcoholics. Psychosom Med. 2003;65:75-85.

31. Tessaro I. et al. Effect of oral administration of low-dose follicle stimulating hormone on hyperandrogenized mice as a model of polycystic ovary syndrome. J Ovarian Res. 2015t 6;8(1):64.

32. Martin-Martin $L S$, et al. An open randomized active-controlled clinical trial with low-dose SKAcytokines versus DMARDs evaluating low disease activity maintenance in patients with rheumatoid arthritis. Drug Design, Development and Therapy. 2017;11:985-94.

\section{Submit your next manuscript to BioMed Central and we will help you at every step:}

- We accept pre-submission inquiries

- Our selector tool helps you to find the most relevant journal

- We provide round the clock customer support

- Convenient online submission

- Thorough peer review

- Inclusion in PubMed and all major indexing services

- Maximum visibility for your research

Submit your manuscript at www.biomedcentral.com/submit

C) Biomed Central 